\title{
Coverage of gingival recession using pouch connective tissue graft technique.
}

\author{
Dr. Yashika Jain MDS \\ (Assistant Professor, Periodontology\&Implantology, S.G.T Dental College \&Research Institute, Gurgaon,India)
}

\begin{abstract}
Cosmetic procedures have become an integral part of periodontal treatment. One of the commonly used esthetic periodontal procedures is coverage of denuded roots. The recession of gingiva is increasingly becoming a more prominent condition in the oral health of many patients and should be treated at its earliest detection. The multi-factorial etiology, decision modality, and current trends followed in treatment of gingival recession are discussed in this presentation. This case report focuses on soft tissue root coverage in class II and class III gingival recession using the pouch surgical procedure. The pouch technique is a minimally invasive periodontal plastic surgical procedure that uses subepithelial connective tissue as a free graft in a pouch beneath the gingival margin, created by sulcular incisions around the involved teeth. In this case report, an alternative technique in treating gingival recession- the tunnel connective tissue graft is presented.
\end{abstract}

Keywords: tunnel technique, connective tissue graft, gingival recession, root coverage, coronally positioned flap.

\section{Introduction}

Recession is defined as the apical migration of the junctional epithelium with exposure of root surfaces. It is a common condition and its extent and prevalence increase with age. It has been estimated that $50 \%$ of the population has 1 or more sites with $1 \mathrm{~mm}$ or more of such root exposure. This prevalence rate increases to greater than $88 \%$ for individuals who are 65 years or older. ${ }^{1}$ Gingival recession can be localized or generalized and be associated with one or more surfaces. The resulting root exposure is not esthetically pleasing and may lead to sensitivity and root caries. Marginal gingival recession, therefore, can cause major functional and aesthetic problems, and should not be viewed as merely a soft tissue defect, but rather as the destruction of both the soft and hard tissue. Treatment proposals for this type of defect have evolved based on the knowledge for healing the gingiva and the attachment system. ${ }^{2}$

Tissue trauma caused by vigorous toothbrushing is considered to be a predominant causative factor for the development of recessions, particularly in young individuals. Traumatizing toothbrushing and tooth malposition are the factors most frequently found to be associated with marginal tissue recession. Other local factors that have been associated with marginal tissue recession are alveolar bone dehiscences, high muscle attachment, frenal pull , plaque and calculus. ${ }^{3}$ The choice of appropriate surgical treatment of gingival recession is according Miller's classification. Miller (1985) described a useful classification of recession defects, taking into consideration the anticipated root coverage that it is possible to obtain. ${ }^{4}$ Surgical root coverage may be achieved by a number of techniques, including pedicle gingival grafts, free autogenous gingival grafts, and connective tissue grafts. Guided tissue regeneration may also be used. In selecting a surgical procedure, it is necessary to evaluate the amount of coverage required for the exposed root . Connective tissue grafts and GTR are applicable to wide and deep gingival recessions and offer esthetically pleasing results. ${ }^{2}$

While complete root coverage can be achieved in Class I and II defects, only partial coverage may be expected in Class III. The predictability of coverage of the exposed root surface is influenced by many factors, including whether the gingival margin is apical to the mucogingival junction (MGJ), whether there is loss of interalveolar septa or interdental gingiva, and the extent of tooth malposition. Several surgical techniques have been proposed for root coverage. Langer and Langer introduced the use of subepithelial connective tissue grafts for root coverage. Root coverage was thought to be difficult to achieve in wide and deep gingival recession areas or in an adjacent gingival recession area with multiple. To minimize incision and reflection of the flap and to provide abundant blood supply to donor tissue the placement of subepithelial donor connective tissue into pouches beneath the papillary tunnel allow for intimate contact of donor tissue to recipient site.Compared to the epithelialized graft, the connective tissue graft is preferable due to less invasive palatal wound and improved esthetic result.

\section{Case History}

A 43 year old male patient reported with the complaint of sensitivity in relation to lower anterior teeth. On examination there was Miller's Class II and Class III recession in relation to 41 and 31[Figure 1]. The patient was not suffering from any systemic disease, non smoker and a minimum of $2 \mathrm{~mm}$ of keratinized gingiva 
was present. A pouch technique for 41 and 31 utilising palatal connective tissue graft for root coverage was planned. Area was anesthetized and root planning was performed in 31 and 41. Using number 15C or 12D blade a sulcular incision adjacent to recession was given. With the help of a curette or small blade a tunnel beneath the adjacent buccal papilla was created. Split thickness pouch apical to tunneled papilla and adjacent radicular surface extending $10-12 \mathrm{~mm}$ apical to recessed gingival area and 6-8mm mesial and distal to denuded root surface was created[Figure 2]. Equivalent size of connective tissue donor was procured from the palate. [Figure3].Using curette, sutures and elevators the connective tissue was placed under the tunnel with portion covering the denuded surface [Figure4]. Mesial and distal ends of donor tissue were secured by gut sutures. The gingival margin of the flap coronally placed and secured by horizontal mattress extends over the contact of the adjacent teeth. Holding suture placed through the overlying gingival tissue and donor tissue to underlying periosteum to stabilize the donor tissue beneath the gingiva. Periodontal dressing used to cover the surgical site and the patient was advised not to brush for $72 \mathrm{hrs}$ in the area of surgery. An ice-pack was given immediately post-operatively and asked to restrain from spitting or rinsing for first few hours. The patient was recalled after $24 \mathrm{hrs}$, three days and then after one week. The pack was removed, the area of operation appeared normal without any trace of sloughing. The patient was asked to report to the clinic every month for six months for routine check up. The healing progressed uneventfully and the gingival recession was totally covered with a beautiful aesthetic result on both side[Figure 5].

\section{Discussion}

Surgical root coverage may be achieved by a number of techniques, including pedicle gingival grafts, free autogenous gingival grafts, and connective tissue grafts. Guided tissue regeneration may also be used. Pedicle gingival grafts require no donor site and offer excellent blood supply. Laterally positioned flaps have been widely used since Grupe and Warren ${ }^{5}$ introduced this method for the treatment of localized gingival recession. In this procedure, the adjacent keratinized gingiva is positioned laterally, and the exposed root surface in the localized gingival recession is covered. The disadvantages of this method are possible bone loss and gingival recession on the donor site. All of these methods are used frequently today, and the use of each one of them is based on its advantage or disadvantage, as well as on the individual surgeon's preference and experience.

At one time, free autogenous gingival grafts were used only to increase the width of keratinized gingiva, not to cover exposed root surface. Possible root coverage was limited to 3-mm width and 3-mm depth with free autogenous gingival grafts. This method was not indicated for root coverage of deep and wide gingival recession areas because of insufficient blood supply to graft. However, a series of procedures modified by Miller and Holbrook and Ochsenbein ${ }^{6}$ demonstrated successful root coverage using free autogenous gingival grafts. Langer and Langer ${ }^{7}$ introduced the use of subepithelial connective tissue grafts for root coverage. Root coverage was thought to be difficult to achieve in wide and deep gingival recession areas or in an adjacent gingival recession area with multiple teeth, but results were satisfactory with this technique. Raetzke ${ }^{8}$ performed connective tissue grafting with the envelope flap and achieved, on average, $80 \%$ root coverage. Nelson ${ }^{9}$ reported an average of $88 \%$ root coverage in areas of extreme gingival recession using subepithelial connective tissue grafts. Jahnke et al $^{10}$ compared the use of gingival grafts and connective tissue grafts in the same patient and found that the amount of coverage and rate of complete coverage was better with the use of connective tissue grafts.

Root coverage using connective tissue grafts has a high success rate and is therefore frequently used. To minimize incision and reflection of the flap and to provide abundant blood supply to donor tissue. The placement of subepithelial donor connective tissue into pouches beneath the papillary tunnel allow for intimate contact of donor tissue to recipient site.

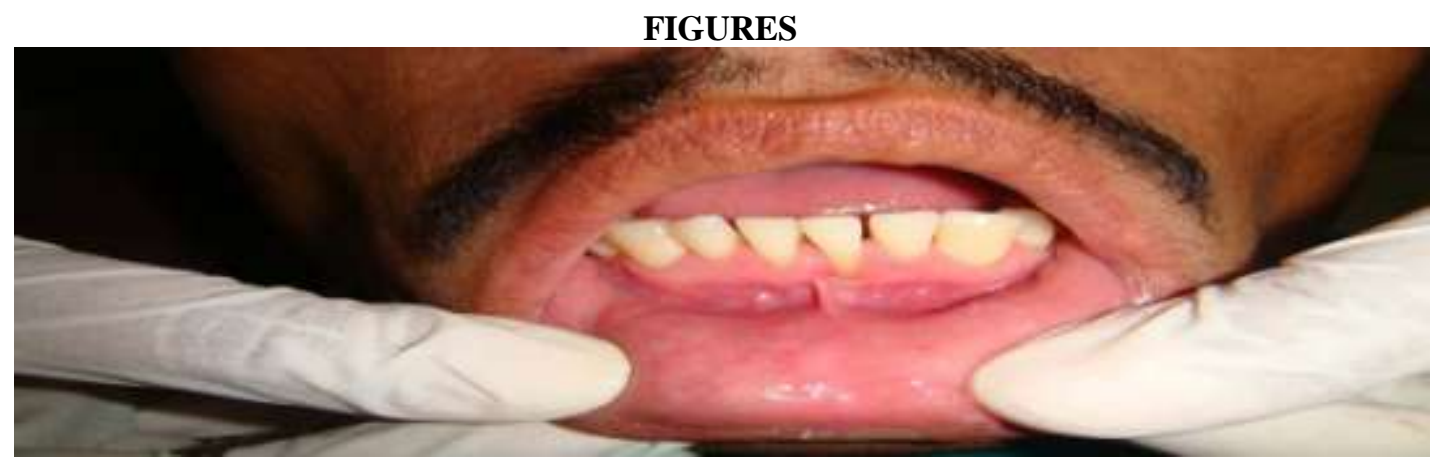

Fig. 1- Class II and Class III gingival recession on the mandibular right and left central incisors. 


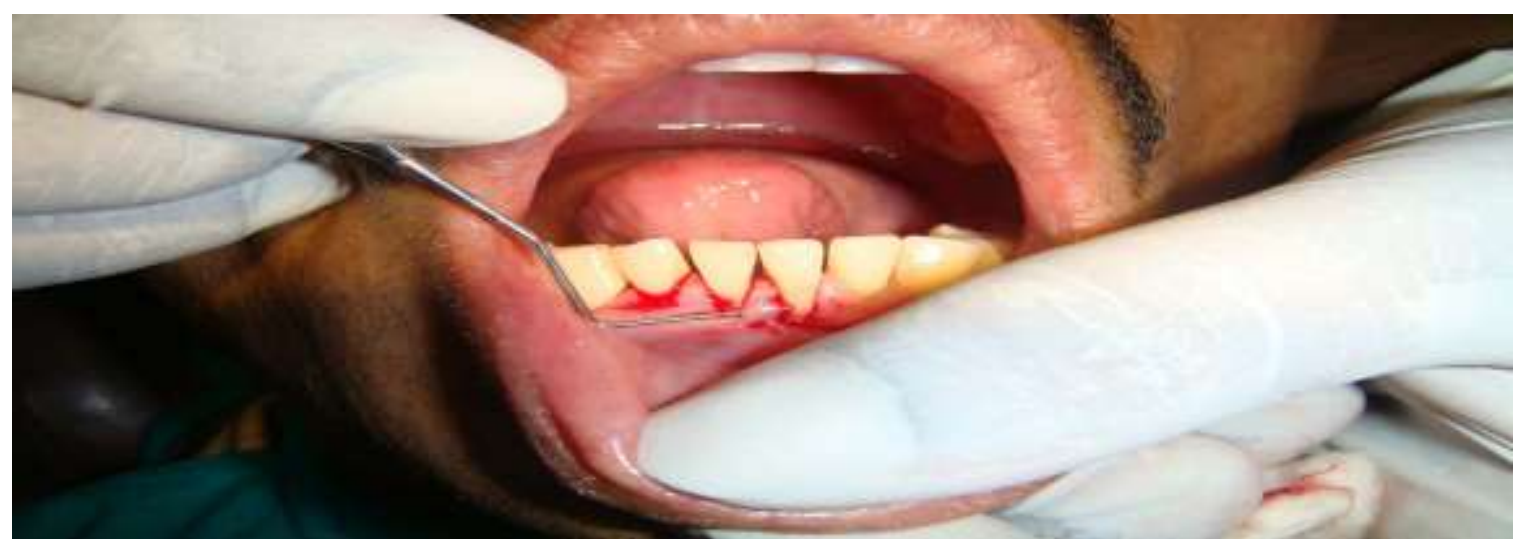

Fig. 2-Preparation of a subepithelial pouch

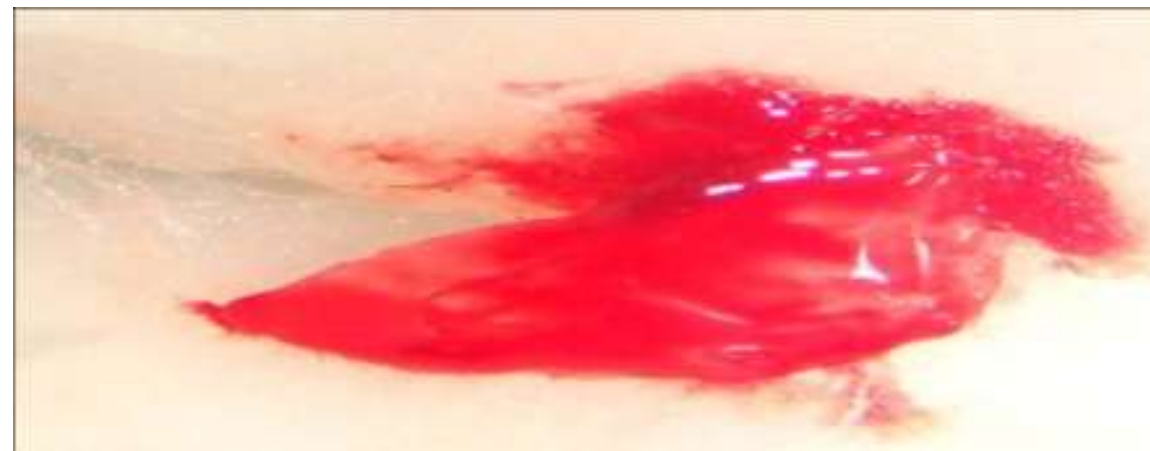

Fig. 3 - CTG after palatal harvesting

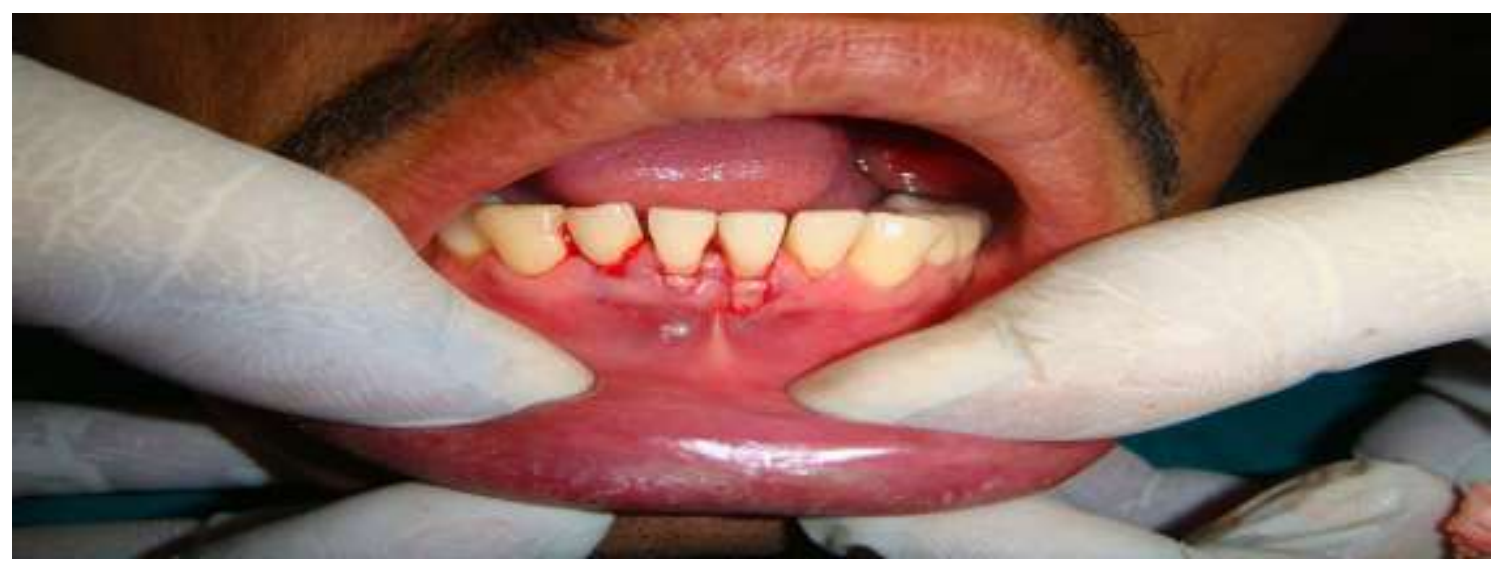

Fig.4 - The CTG is inserted in the tunnel and the flap is advanced and sutured with the graft

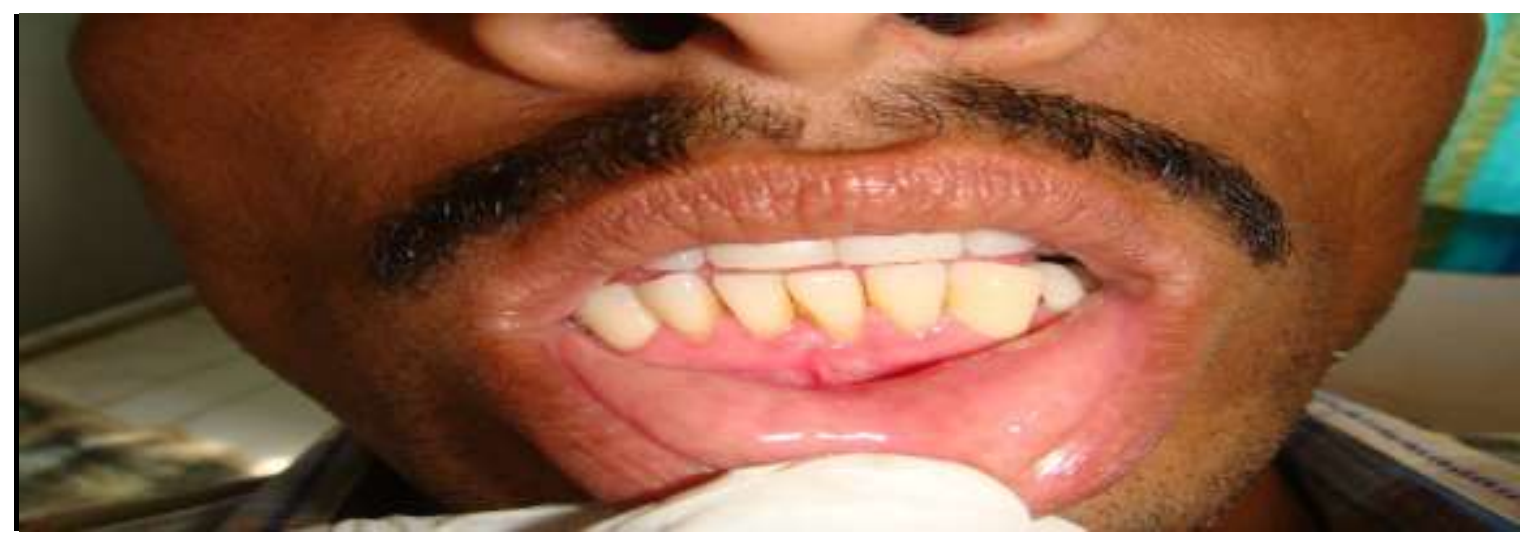

Fig. 5 - Right and left mandibular central incisors postoperative $6 \mathrm{mth}$ 


\section{Conclusion}

The surgical technique of choice depends on several factors, each having advantages and disadvantages. The connective tissue graft procedure led to achievement of satisfying clinical results in the presented case. The application of tunnel technique due to its minimal invasive approach quickens the healing process and allows better aesthetic results.

\section{References}

[1] Dr. J Leake,Dr. J. Mayhall Treatment of Gingival Recession: An Analysis of Current Literature and Recommendations

[2] Andre P. Saadoun Current Trends In Gingival Recession Coverage- PartI The Tunnel Connective Tissue Graft Prac Proced Aesthet Dent 2006;18(7):433-438

[3] Moawia M. Kassab,Robert E.,Cohen The etiology and prevalence of gingival recession JADA, 2003Feburary;(134):220-225

[4] K. Kotsilkov, Chr. Popova The Application Of A Minimal Invasive Connective Tissue Graft Technique (envelope technique) In A Treatment Of A Gingival Recession. Journal of IMAB - Annual Proceeding (Scientific Papers) 2008; book 2:16-18.

[5] Grupe HE, Warren RE. Repair of gingival defects by a sliding flap operation. J Periodontol 1956;27:92-95.

[6] Holbrook T, Ochsenbein C. Complete coverage of denuded root surfaces with a one-stage gingival graft. Int $\mathrm{J}$ Periodontics Restorative Dent 1983;3(3):9-27.

[7] Langer B, Langer L. Subepithelial connective tissue graft technique for root coverage. J Periodontol 1985;56:715-20.

[8] Raetzke PB. Covering localized areas of root exposure employing the envelope technique. J Periodontol 1985;56:397-402.

[9] Nelson SW. The subpedicle connective tissue graft -A bilaminar reconstructive procedure for the coverage of denuded root surfaces. J Periodontol 1987;58:95-102.

[10] Jahnke PV, Sandifer JB, Gher ME, et al. Thick free gingival and connective tissue autografts for root coverage. J Periodontol $1993 ; 64: 315-22$. 